\title{
PERILAKU KOLOM BETON RINGAN AKIBAT BEBAN AKSIAL DAN MOMEN
}

\author{
Oleh: Muhammad Ryan Iskandar ${ }^{1}$, Fajar Purwoko² \\ E-mail: muhammad.ryan01@gmail.com¹, fajar200986@gmail.com²
}

\begin{abstract}
ABSTRAK: Kelebihan dari penggunaan kolom komposit pipa baja dan beton salah satunya dapat menghambat terjadinya tekuk pada pipa baja dan meningkatkan kapasitas dukung kolom. Penelitian kolom penampang lingkaran kali ini dilakukan untuk mengetahui pengaruh pengisian beton ringan ke dalam pipa baja dan menjadi struktur komposit. Beton ringan yang digunakan berupa beton non pasir. Keunggulan beton non pasir adalah pembuatannya mudah dan murah. Penelitian dilakukan secara eksperimental dan secara numerik dengan menggunakan program elemen hingga non linier, kemudian membandingkan hasilnya. Benda uji program eksperimental terdiri dari 3 kolom pipa baja dan 6 kolom komposit pipa baja-beton non pasir. Pipa baja mempunyai diameter luar 113,2 $\mathrm{mm}$ dengan ketebalan tabung $2 \mathrm{~mm}$. Benda uji program numerik terdiri dari 12 kolom komposit dengan variabel panjang kolom dan eksentrisitas beban.
\end{abstract}

Kata kunci: Beton ringan, Pipa baja, Beton non pasir, Kolom Komposit.

\section{PENDAHULUAN}

\subsection{Latar Belakang}

Kolom merupakan komponen struktur yang sangat penting dalam dunia konstruksi, yang berfungsi menyalurkan beban dari balok dan plat ke fondasi kemudian diteruskan ke tanah dasar. Untuk itu diperlukan suatu konstruksi kolom yang kuat dan kaku untuk menopang bangunan. Penggunaan kolom yang langsing seperti pipa baja dirasa kurang baik karena adanya potensi tekuk (buckling) dari pipa baja tersebut. Untuk menghindari hal tersebut diperlukan suatu material pengisi pipa agar dapat mengurangi pengaruh tekuk lokal tersebut. Selain itu dengan adanya material pengisi pipa, kuat tekan pipa terhadap gaya aksial juga akan meningkat, karena terjadi tegangan triaksial pada material pengisi.

Dewasa ini telah berkembang teknologi beton non-pasir, yaitu material beton yang diperoleh dari menghilangakan pasir. Dengan tidak digunakannya pasir, beton yang dihasilkan memiliki rongga-rongga kosong di antara agregat kasar yang tersebar merata dalam seluruh massa beton. Tidak adanya pasir dalam beton menyebabkan berat beton menjadi berkurang, sehingga secara keseluruhan berat bangunan menjadi lebih ringan. Selain dari itu penggunaan beton non pasir sebagai pengisi pipa baja juga lebih ekonomis.

Penelitian telah dilakukan secara eksperimental di laboratorium memberikan hasil yang sangat dekat dengan kenyataan di lapangan. Dari metode inipun sering muncul formula-formula empiris yang praktis untuk digunakan perencana, namum dibutuhkan biaya yang cukup mahal dan waktu yang relatif lama untuk mengadakan penelitian semacam ini. Selain itu beberapa variabel sulit untuk diamati. Metode lain yang memberikan hasil cukup baik adalah metode numerik. Dengan metode ini peneliti dapat mengeksplorasi lebih banyak parameter tanpa harus menambah biaya yang berarti. Bahkan variabel yang sulit untuk diamati di laboratorium menjadi mudah dilakukan di sini. Masalah kesahihan hasil numerik dengan kenyataan dapat dijembatani dengan memverifikasi hasil numerik dengan hasil penelitian laboratorium yang sudah ada. 
Dari uraian di atas, akan dilakukan penelitian terhadap perilaku pipa baja yang digunakan sebagai kolom yang diisi beton non pasir. Penelitian ini dianggap perlu, karena bisa digunakan sebagai referensi penggunaan pipa baja yang diisi beton ringan.

\subsection{Batasan Masalah}

Batasan masalah yang digunakan pada penelitian ini adalah sebagai berikut:

1. Bahan pembuat tabung berupa baja dengan tampang lingkaran mempunyai diameter luar 113,2 mm dengan tebal $2 \mathrm{~mm}$

2. Parameter yang divariasikan pada tabung berupa panjang kolom, dengan panjang berturut-turut $0.25 \mathrm{~m}, 0.5 \mathrm{~m}$, dan $1 \mathrm{~m}$.

3. Beban yang diterapkan berupa tekan konsentrik dan eksentrik, dengan nilai eksentrisitas $0 \mathrm{~mm}$ dan $100 \mathrm{~mm}$ untuk metode eksperimental, dan eksentrisitas 0 $\mathrm{mm}, 25 \mathrm{~mm}, 50 \mathrm{~mm}$ dan $100 \mathrm{~mm}$ untuk metode numerik elemen hingga.

4. Beban yang dikenakan hanya beban statik dan lendutan yang ditinjau pada arah aksial dan lateral.

5. Pembebanan jangka pendek, sehingga pengaruh creep dan redistribusi tegangan pada beton dan baja diabaikan

6. Parameter beton non pasir yang digunakan dalam analisis numerik menggunakan parameter untuk beton normal tanpa kekangan yang tersedia pada program ATENA.

\section{TINJAUAN PUSTAKA}

\subsection{Kolom Komposit Pipa Baja-Beton}

Pemakaian kolom komposit pipa baja diisi beton (concrete filled stell tubes- CFST) sudah dimulai pada awal abad 19, yaitu untuk struktur-struktur gedung dan jembatan. Tabung baja diisi dengan beton dipakai pada struktur-struktur tersebut untuk mendapatkan stabilitas yang tinggi (Shams dan Saadeghvaziri, 1997 dalam Muslikh, 2005). Keuntungan lain dari penggunaan tabung baja yang diisi dengan beton ini antara lain (Tomii et al.,1973; Goode, 1994 dalam Muslikh, 2005) tidak terjadinya cover spalling beton, tabung baja sekaligus berperan sebagai tulangan dan formwork, mencegah terjadinya tekuk lokal pada baja, meningkatkan kecepatan konstruksi, kolom komposit dapat mendukung beban lebih besar untuk tiap satuan luas dibandingkan dengan kolom beton tipe lain dengan dimensi sama.

\subsection{Beton Non Pasir}

Beton non pasir adalah bentuk sederhana beton ringan yang dapat dicapai dengan menghilangkan fraksi agregat halus dalam adukan/campuran beton normal. Kuat tekan beton non pasir sangat tergantung dengan berat jenisnya yang dipengaruhi oleh jumlah semen portland per meter kubiknya. Menurut Raju (1983) dalam Rum (2009) kuat tekan beton non pasir $7 \mathrm{MPa}$ untuk berat jenis $1,9 \mathrm{~kg} / \mathrm{dm}^{3}$ dan $14 \mathrm{MPa}$ untuk berat jenis 2,1 $\mathrm{kg} / \mathrm{dm}^{3}$ pada umur beton 28 hari.

Kepadatan pada beton non pasir tergantung pada gradasi agregat kasar yang digunakan dan secara umum antara $60-75 \%$ dari beton normal. Bentuk kerikil seragam mempunyai kelebihan dalam tekstur permukaan yang lebih rapat, juga kuat tekan yang dihasilkan akan lebih baik karena di antara agregat terjadi interlocking.

Kuat tekan beton non-pasir lebih rendah daripada beton normal, sehingga penggunaan beton non-pasir hanya sebatas untuk bangunan non struktural misalnya tembok atau 
dibentuk bata tembok, apabila digunakan untuk struktur maka digunakan baja tulangan atau diberi perkuatan yang lain.

Subkhannur (2002) melakukan penelitian dengan menggunaka agregat dari kerikil Merapi menghasilkan beton non pasir dengan berat berkisar antara 1.790 sampai 2.240 $\mathrm{Kg} / \mathrm{m} 3$ dengan rongga yang terbentuk berkisar antara 1,23 sampai $25,23 \%$. Adapun pada penelitian yang dilakukan oleh Pradono (2007), beton yang dihasilkan mempunyai berat antara 1.849 sampai $2.377 \mathrm{Kg} / \mathrm{m} 3$ dengan rongga yang terbentuk berkisar antara 1,24 sampai $27,34 \%$.

\subsection{Pemodelan Elemen Hingga Kolom Komposit}

Muslikh (2005) memodelkan perilaku kolom tubular komposit baja beton ringan agregat ALWA dengan menggunakan program elemen hingga nonlinier ATENA. Kolom tubular komposit yang terdiri dari tabung baja dan inti beton dimodelkan secara terpisah (discrete), untuk mensimulasi adanya bond di antara kedua bagian tersebut. Inti beton dan tabung baja dimodelkan dengan elemen 8 titik nodal hexahedron, sedangkan hubungan antara tabung baja dengan inti beton dimodelkan dengan elemen interface 3D. Hasil yang diperoleh cukup baik sesuai dengan hasil yang diperoleh dari benda uji eksperimental yang digunakan sebagai perbandingan. Analisis elemen hingga nonlinier yang dilakukan pada umumnya dapat memprediksi kapasitas kolom tubular komposit, maupun komponen-komponennya (tabung baja dan inti beton), tetapi tidak dapat memberikan descending part kurva dan daktilitas sebagaimana yang terjadi pada hasil eksperimen.

Omar, dkk (2003) melakukan penelitian terhadap perilaku batang CFST dalam menahan lentur dengan metode elemen hingga menggunakan program Lusas. Benda uji baja menggunakan baja hollow segi empat dengan memperhitungkan jari-jari sudut. Pemodelan baja dilakukan dengan elemen shell tebal empat nodal dengan material bahan elasto-plastis sempurna dengan kriteria keluluhan dari Von-Mises. Pemodelan material beton pengisi 3D continuum solid delapan nodal dengan pemodelan retak menggunakan model multi-retak (multi crack-concrete). Lekatan (bond) dimodelkan dengan properties elastic joint yang di nonaktifkan selama analisis. Model finite elemen dapat memprediksi perilaku batang dengan baik untuk balok dengan rasio $b / t=18-60$. Menurut Omar (2003), pemodelan numerik adalah motode yang paling cocok untuk mengembangkan data yang dibutuhkan untuk menghasilkan rekomendasi desain.

\section{LANDASAN TEORI}

\subsection{Teori Kolom}

Kolom adalah elemen struktur yang mendukung beban aksial disamping momen. Menurut Euler kolom dapat rusak / patah oleh karena tekuk apabila beban itu sama dengan atau lebih besar dari beban kritik $\left(P_{c}\right)$, kolom demikian disebut kolom panjang dan sebaliknya disebut kolom pendek.

$$
P_{c}=\frac{\pi^{2} \cdot E I}{\left(k \cdot l_{u}\right)^{2}}
$$

Bila kolom lentur ( $E$ I rendah atau $l_{u}$ tinggi) akan semakin memudahkan kolom itu rusak oleh karena tekuk. Upaya untuk menghindarkan kerusakan tekuk, dengan 
memadukan antara luasan tampang dan panjang batang. Parameter tekuk diindikasikan oleh suatu faktor yang disebut faktor kelangsingan (slenderness ratio) batang $\left(k \cdot l_{u} / r\right)$, semakin besar faktor ini akan mengindikasikan adanya kerusakan tekuk. Yang perlu diketahui bahwa kerusakan tekuk terjadi di bawah kekuatan tampangnya.

\subsection{Kolom Beton Terkekang}

Mekanisme kolom beton terkekang didasarkan pada prinsip bahwa beton mengalami tegangan dari berbagai arah. Pada kolom yang mengalami tekan aksial saja, baik kolom terkekang atau tidak, respon yang timbul adalah terjadinya ekspansi lateral pada kolom tersebut. Hal ini terjadi karena adanya efek Poisson's rasio. Pada kolom beton tanpa kekangan, ekspansi ini terus bekembang sampai tercapainya kuat tarik beton tersebut sehingga keruntuhan beton dimulai. Pada kolom dengan kekangan ekspansi tersebut dihambat. Hal ini terjadi karena adanya perbedaan modulus elastisitas, Poisson's ratio, dan kapasitas dari dari bahan pengekang tersebut. Dengan adanya hambatan ini berarti menunda proses keruntuhan beton seiring bertambahnya beban.

Richart et al. (1928) dalam Paulay and Park (1974) melakukan penelitian terhadap perilaku beton yang mengalami tiga tegangan utama dengan arah yang saling tegak lurus satu sama lain. Benda uji silinder beton dibebani secara aksial sambil diberi tekanan air pada arah lateralnya. Hasil penelitian mereka menghasilkan formula:

$$
f^{\prime}{ }_{c c}=f^{\prime}{ }_{c}+4,1 f^{\prime}{ }_{1}
$$

Dimana $f^{\prime}{ }_{c c}$ adalah kuat tekan beton terkekang, $f^{\prime}{ }_{c}$ adalah kuat tekan beton normal, dan $f^{\prime}{ }_{1}$ adalah tekanan kekangan lateral.

Dari formula di atas terlihat bahwa kekangan lateral memberikan peningkatan terhadap naiknya kuat tekan beton. Semakin tinggi nilai kekangan dari cairan, semakin tinggi nilai kuat tekan beton terkekang. Dengan model benda uji silinder tekanan kekangan dari cairan dapat bekerja secara seragam.

\subsection{Metode Elemen Hingga}

Metode penelitian dengan melakukan eksperimen dengan skala penuh secara intensif, selain mahal dan membutuhkan waktu yang lama, juga sangat sulit untuk memperoleh seluruh informasi yang dibutuhkan untuk dipakai dalam pengambilan keputusan. Pendekatan lain yang dapat digunakan untuk melakukan analisis struktur dengan menggunakan metode elemen hingga nonlinier (nonlinear finite element method). Metode elemen hingga diperkenalkan sekitar tahun 1960 oleh Argyris Clough dan Zienkiewics (Rusinowski, 2005). Pada analisis elemen hingga nonlinier dimungkinkan untuk mengontrol berbagai parameter lebih baik, dibandingkan dengan eksperimen.

Elemen yang tersedia pada program ATENA dapat dibagi dalam tiga kelompok, yaitu elemen datar (untuk 2D, 3D dan axysimmetri), elemen solid 3D (untuk 3D) dan elemen special (pegas, kabel, gap / interface dan sebagainya). Elemen-elemen tersebut disusun menggunakan formulasi isoparametrik, dengan fungsi interpolasi linier dan / atau kuadrat. 


\section{METODOLOGI PENELITIAN}

\subsection{Program Eksperimental}

Penelitian dilakukan dengan membuat benda uji kolom komposit, berupa tabung baja diisi dengan beton non pasir dengan variasi terhadap panjang kolom dan eksentrisitas pembebanan. Panjang model kolom komposit dibedakan atas tiga jenis, yaitu $250 \mathrm{~mm}, 500 \mathrm{~mm}$ dan $1000 \mathrm{~mm}$. Variasi pembebanan dibagi menjadi dua, yaitu pembebanan konsentrik (eksentrisitas 0) dan pembebanan eksentrik (eksentrisitas 100 $\mathrm{mm}$ ). Sebagai perbandingan, juga dilakukan pengujian konsentrik terhadap pipa baja yang tidak diisi beton non pasir yang panjangnya dibedakan menjadi tiga jenis.

Material tabung baja yang dipakai merupakan jenis pipa galvanis (galvanized pipe) dengan sambungan las dan mempunyai diameter luar 113,2 mm dengan ketebalan $2 \mathrm{~mm}$. Beton yang dipakai sebagai inti beton pada kolom komposit ini merupakan beton nonpasir dengan spesifikasi kerikil lolos saringan $20 \mathrm{~mm}$ dan tertahan disaringan $10 \mathrm{~mm}$. Semen yang dipakai merupakan semen Portland type I dengan merk Indocement.

\subsection{Program Numerik}

Tujuan dilakukannya analisis elemen hingga ini adalah untuk memperluas interpretasi hasil dan observasi dari eksperimen yang telah dilakukan. Dalam hal ini dipakai suatu program komputer komersial elemen hingga, yaitu ATENA 2.1.9 dari Cervenka Consulting, Cekoslovakia (Cervenka et al, 2000). Data properties tabung baja dan inti beton yang digunakan sama dengan program eksperimental. Panjang kolom komposit dibedakan atas tiga jenis, sedangkan variasi pembebanan dibagi menjadi empat jenis.

\section{HASIL DAN PEMBAHASAN PROGRAM EKSPERIMEN}

\subsection{Pengujian Material}

Inti beton yang dipakai untuk model kolom komposit dibuat dari beton non pasir. Benda uji kuat tekan beton berbentuk silinder dengan ukuran diameter $150 \mathrm{~mm}$ dan tinggi $300 \mathrm{~mm}$. Uji kuat tekan silinder beton dilakukan pada umur 28 hari. Pada Tabel 1 dapat dilihat hasil pengujian karakteristik silinder beton. Selain pengujian kuat tekan, juga dilakukan pengujian kuat tarik belah beton terhadap silinder dengan ukuran diameter $150 \mathrm{~mm}$ dan tinggi $300 \mathrm{~mm}$. Nilai yang diperoleh untuk kuat tarik belah beton $1,20 \mathrm{MPa}$.

Tabel1. Hasil Uji Tekan Beton Non Pasir

\begin{tabular}{|l|l|l|}
\hline No & Jenis Pengujian & Nilai \\
\hline 1 & Berat volume $\left(\mathrm{kg} / \mathrm{m}^{3}\right)$ & $2.116,41$ \\
\hline 2 & Kuat tekan $\left(f_{c}^{\prime}, \mathrm{MPa}\right)$ & 12,788 \\
\hline 3 & $\begin{array}{l}\text { Kuat tarik }\left(\text { splitting test) }\left(f_{c t},\right.\right. \\
\mathrm{MPa})\end{array}$ & 1,2025 \\
\hline 4 & Modulus Elastisitas $\left(E_{c}, \mathrm{MPa}\right)$ & $10.889,37$ \\
\hline
\end{tabular}

Pengujian kuat tarik baja dilakukan untuk mengetahui tegangan dan regangan tabung baja, maka dari tabung baja tersebut dibuat specimen berbentuk coupon dengan tebal $12 \mathrm{~mm}$ yang selanjutnya dilakukan pengujian tarik dengan mesin tarik 
sesuai dengan ketentuan menurut ASTM E 8M. Pada Tabel 2 diberikan nilai tegangan leleh tabung baja.

Tabel 2. Tegangan Leleh Tabung Baja

\begin{tabular}{|c|c|c|c|}
\hline No & $\begin{array}{l}\text { Teg. Leleh } \\
f_{y}(\mathrm{MPa})\end{array}$ & $\begin{array}{l}\text { Teg. Max } f_{u} \\
(\mathrm{MPa})\end{array}$ & $\begin{array}{l}\text { Regangan } \\
(\varepsilon)(\%)\end{array}$ \\
\hline 1 & 361,13 & 385,67 & 29,30 \\
\hline 2 & 354.93 & 380,02 & 31,26 \\
\hline
\end{tabular}

\subsection{Pengujian Kolom Komposit}

\subsubsection{Hubungan beban-perpindahan}

Hasil pengujian dinyatakan dalam hubungan beban-perpindahan (displacement) vertikal, seperti ditunjukkan dalam Gambar 1. Pengujian pada kolom K1-A dihentikan pada beban $425 \mathrm{kN}$ karena keterbatasan kapasitas alat, sehingga descending part tidak dapat diketahui. Dari Gambar 1 terlihat untuk kolom tanpa inti beton, setelah mencapai beban leleh kuat dukung kolom langsung turun (degrading stiffness). Hal ini disebabkan karena kegagalan yang terjadi adalah kegagalan tekuk (buckle).

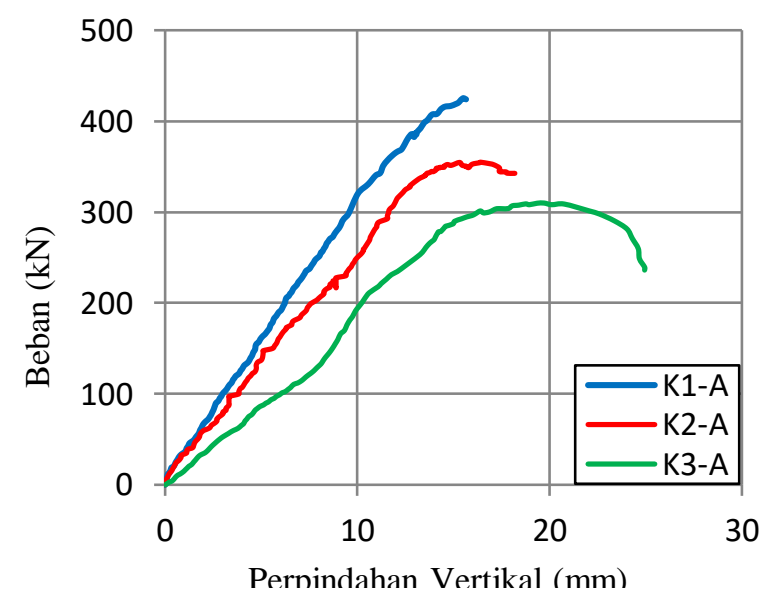

Gambar 1. Diagram beban-perpindahan kolom dengan pembebanan konsentrik

\subsubsection{Pengaruh eksentrisitas}

Pengaruh eksentrisitas beban terhadap perilaku mekanik kolom komposit pipa baja-beton non pasir dilakukan dengan memberikan eksentrisitas beban aksial. Dalam hal ini diambil nilai eksentrisitas $0 \mathrm{~mm}$ (konsentrik) dan $100 \mathrm{~mm}$. Pada Gambar 2 ditunjukkan hubungan beban-perpindahan aksial untuk kolom K1-D, K2-D dan K3-D yang dibebani eksentrik. Dari gambar tersebut terlihat bahwa pengaruh eksentrisitas sangat besar dalam menurunkan kapasitas dukung kolom. Hal ini karena interaksi momen-gaya yang lebih berperan terhadap kapasitas dukungnya adalah bajanya, karena beton sendiri tidak mampu menahan tarik akibat lentur. Dapat dilihat pula untuk kolom K2-D lebih kecil dibandingkan dengan kolom K3-D, hal ini dikarenakan ketika pembebanan, pada sepatu/dudukan beban yang terbuat dari plat besi bengkok karena tidak mampu menahan beban. Pada Tabel 3 dapat dilihat beban ultimit dan displacement vertikal masing-masing benda uji. 


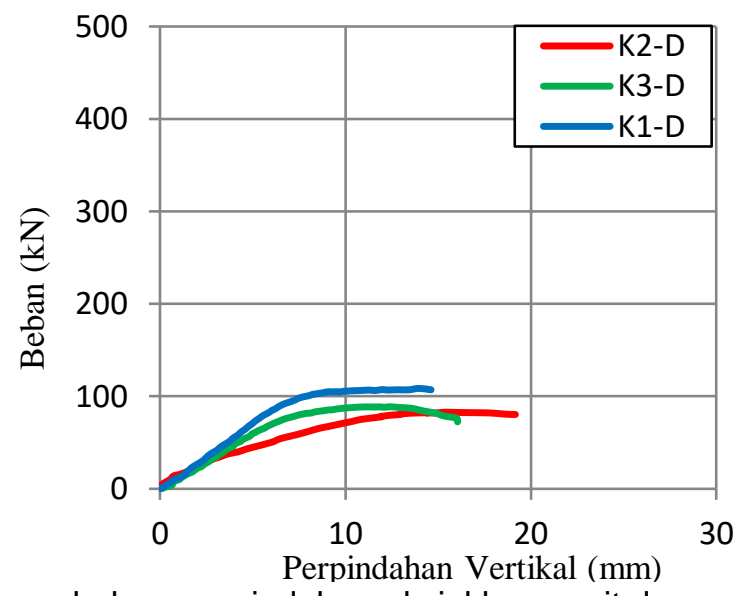

Gambar 2. Diagram beban-perpindahan aksial komposit dengan beban eksentrik

Tabel 3. Hasil Pengujian Program Eksperimental

\begin{tabular}{|l|l|l|l|}
\hline $\begin{array}{l}\text { Benda } \\
\text { Uji }\end{array}$ & $\begin{array}{l}\text { Beban } \\
\text { Ultimit }(\mathrm{kN})\end{array}$ & $\begin{array}{l}\text { Displacement } \\
\text { Vertikal }(\mathrm{mm})\end{array}$ & $\begin{array}{l}\text { Selisih } \\
(\%)\end{array}$ \\
\hline K1-A & 425,2 & 15,49 & 100,00 \\
\hline K2-A & 354,9 & 16,39 & 100,00 \\
\hline K3-A & 309,9 & 19,71 & 100,00 \\
\hline K1 & 270,3 & 5,86 & 63,57 \\
\hline K2 & 248,7 & 10,28 & 70,08 \\
\hline K3 & 230,5 & 12,93 & 74,38 \\
\hline K1-D & 108,6 & 12,69 & 25,54 \\
\hline K2-D & 82,8 & 15,65 & 23,33 \\
\hline K3-D & 88,8 & 12,42 & 28,65 \\
\hline
\end{tabular}

\subsection{Pola Runtuh}

Pola runtuh kolom komposit pipa baja-beton non pasir akibat beban konsentrik menunjukkan keruntuhan geser dan aksial. Untuk kolom K1-A, pola runtuhnya belum bisa diamati karena pengujian dihentikan akibat keterbatasan kapasitas alat. Pada kolom K2-A bidang geser terjadi pada sekitar sepertiga panjang dari ujung kolom, yang terjadi pada salah satu ujung. Keruntuhan kolom K3-A menunjukkan keruntuhan tekan yang terjadi secara mencolok pada ujung kolom. Nampak bahwa lokasi keruntuhan terjadi secara acak, dan tidak terjadi di tengah kolom komposit. Hal ini dikarenakan pengaruh beton non pasir yang tidak seragam di dalam pipa baja, selain itu adanya pengaruh pengelasan pada ujung kolom. Gambar pola runtuh bias dilihat pada Gambar 3. 

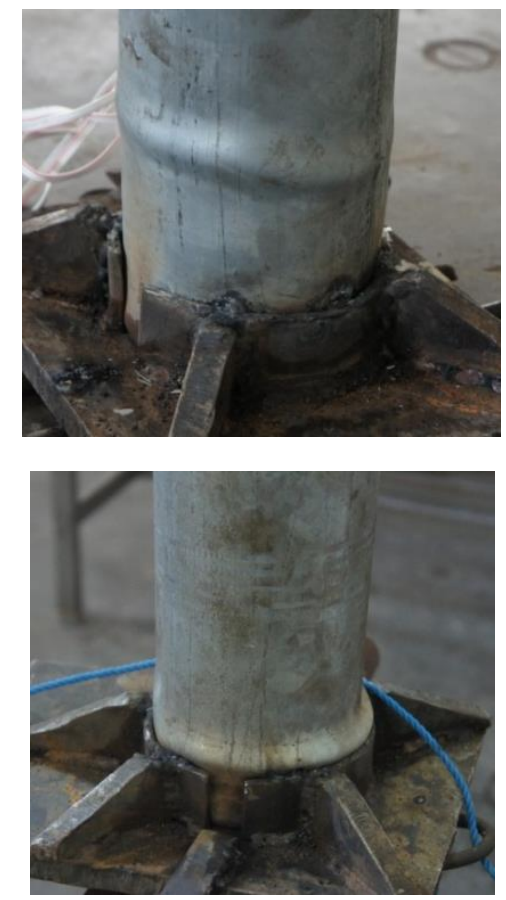

Gambar 3. Pola runtuh kolom K2-A dan K3-A

\section{HASIL DAN PEMBAHASAN PROGRAM NUMERIK}

\subsection{Pemodelan dan Input Elemen Hingga}

Pemodelan elemen hingga dilakukan secara Graphical User Interface (GUI) dengan bantuan program GID, yang berinteraksi dengan program ATENA. Dalam hal ini program GID dipakai untuk melakukan gambar geometri, input material, kondisi batas (boundary condition) dan mesh elemen hingga untuk analisis nonlinier tiga dimensi selanjutnya diproses oleh software ATENAWin. Model elemen hingga non linier ini menggunakan pendekantan smeared cracking model dengan model solid 3 dimensi (3D).

Beton dimodelkan sebagai Concrete dengan jenis material prototype CC3DNonlinCementitious2. Karena keterbatasan data tentang parameter beton non pasir, maka parameter yang digunakan dalam program ATENA menggunakan parameter untuk beton normal tidak terkekang. Parameter beton non pasir pada pemodelan ini dapat dilihat pada Tabel 4.

Pipa baja dimodelkan sebagai material Steel dengan jenis material prototype CC3Dbilinear Stee/VonMisses. Parameter kuat tarik pipa baja menggunakan diagram tegangan-regangan bilinier hasil idealisasi pengujian kuat tarik eksperimen. Nilai kuat tarik baja digunakan sama seperti hasil eksperimen.

Blok beban pada pengujian eksperimen digunakan sebagai media untuk menghubungkan kolom dengan tumpuan / perletakan dan juga berfungsi untuk memberikan eksentrisitas pada kolom. Blok beban dibuat kuat dan kaku agar tidak terjadi kegagalan dan dapat meratakan beban. Pada pemodelan dengan program GID, blok beban sangat diperlukan untuk menyalurkan beban ke kolom karena beban yang yang diterapkan pada program ini berupa beban titik (node). Plat baja dimodelkan sebagai material Elast/sotropic dengan jenis material prototype CC3DElast/sotropic. 
Nilai modulus elastisitas diambil sebesar 200.000.000 MPa, agar kaku dalam mendistribusikan beban perpindahan translasi vertikal.

Elemen interface dipakai material ATENA dengan kode 3DInterface, dengan nilai kekakuan normal dan tangensial sebesar $1 \mathrm{E}+7$ (Cervenka et al, 2000). Nilai koefisien friksi diambil sebesar 0,20 (Johansson et al, 2001, dalam Muslikh,2005).

Tabel 4. Nilai Parameter Beton Non Pasir

\begin{tabular}{|l|l|}
\hline \multicolumn{1}{|c|}{ Parameter } & \multicolumn{1}{c|}{ Nilai } \\
\hline Kuat tekan & $-12,788$ \\
\hline Modulus Elastisitas & 10889,37 \\
\hline Rasio Poisson & 0,19 \\
\hline Kuat tarik & 1,2025 \\
\hline Energi fraktur & 0,0003197 \\
\hline Fixed crack & 0,7 \\
\hline Regangan plastis & $-0,001174$ \\
\hline Onset of crushing & $-3,8365$ \\
\hline Critical compressive & $-0,0005$ \\
\hline Eksentrisitas & 0,52 \\
\hline $\begin{array}{l}\text { Direction of plastic } \\
\text { flow }\end{array}$ & 0 \\
\hline Density & 0,0021164 \\
\hline Thermal expansion & 0,000012 \\
\hline
\end{tabular}

\subsection{Hubungan Beban-Perpindahan}

Berdasarkan hasil analisis non linier elemen hingga dengan program ATENA diperoleh hubungan beban perpindahan vertikal seperti terlihat pada Gambar 4 sampai Gambar 6.

Kolom K1-A merupakan kolom komposit dengan pembebanan konsentrik. Pada Gambar 4. disajikan hasil analisis elemen hingga nonlinier untuk kolom K1-A dan K1-D serta hasil eksperimennya sebagai pembanding. Nampak pada gambar, bahwa hasil analisis numerik untuk kolom komposit K1-A memiliki selisih sedikit lebih rendah sebesar 4,05\% dibandingkan hasil eksperimen. Pada kolom K1-D dapat dilihat bahwa besarnya kapasitas komposit hasil analisis hampir sama dengan hasil eksperimen, dengan selisih $3,13 \%$ lebih besar. Kelengkungan kurva hasil analisis numerik juga menunjukkan hasil yang hampir sama dengan hasil eksperimen, hanya ada perbedaan pada akhir kurva menunjukkan hasil eksperimen lebih landai. 


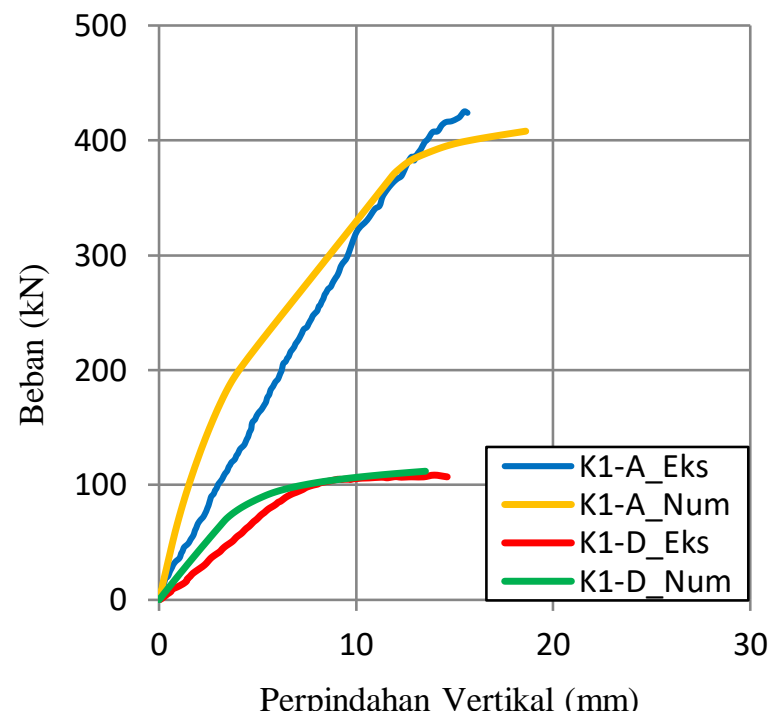

Gambar 4. Diagram beban-perpindahan kolom K1-A dan K1-D

Hasil analisis elemen hingga non linier untuk kolom K2-A dan K2-D ditunjukkan pada Gambar 5. Dapat dilihat besarnya kapasitas komposit hasil hampir sama dengan hasil eksperimen, dengan selisih 0,87 \% lebih besar. Walau demikian, kurva hasil analisis numerik menunjukkan kekakuan yang lebih besar dibandingkan hasil eksperimen, terutama pada bagian elastik. Kurva hasil analisis kolom K2-D memberikan hasil puncak beban yang lebih besar dari hasil eksperimen, dengan selisih $23,19 \%$. Perbedaan yang besar ini disebabkan karena pada eksperimen, ketika pembebanan dilakukan, sepatu/dudukan beban yang terbuat dari plat baja bengkok karena tidak mampu menahan beban.

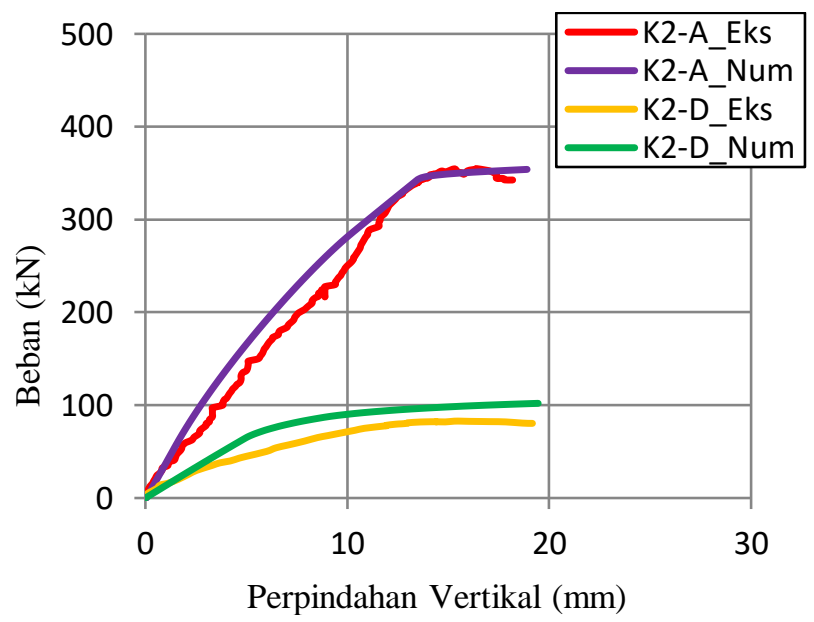

Gambar 5. Diagram beban-perpindahan kolom K2-A dan K2-D

Kolom K3-A memiliki panjang $1000 \mathrm{~mm}$. Elemen yang dianalisis sebanyak 1120 elemen dan 1551 nodes. Pada Gambar 6 terlihat bahwa hasil analisis numerik lebih rendah 3,84\% dibandingkan eksperimen. Kekakuan awal hasil analisis numerik hampir sama dengan hasil eksperimental. Setelah mencapai kelelehan, kurva descending part pada program numerik terlihat mendekati landai, sedangkan pada eksperimental terjadi penurunan. Pada kolom K3-D terlihat bahwa beban puncak hasil analisis numerik lebih besar 10,36 \% dibandingkan hasil eksperimen. Dari gambar terlihat bahwa kolom hasil analisis numerik mempunyai kekakuan yang hampir sama pada awal bagian elastik, 
tetapi makin mendekati puncak perbedaan kekakuannya makin besar dibandingkan hasil eksperimen.

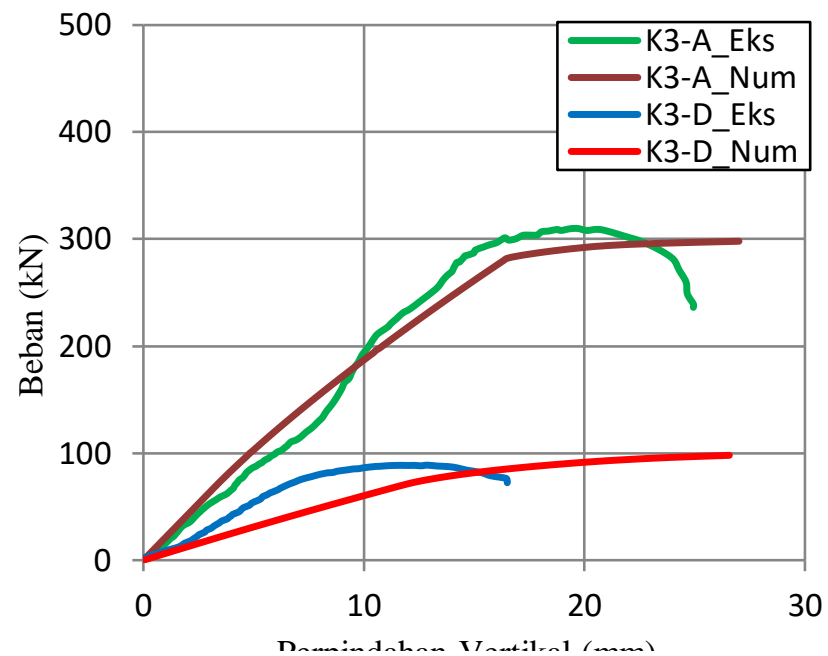

Gambar 6. Diagram beban-perpindahan kolom K3-A dan K3-D

\subsection{Pengaruh Eksentrisitas}

Pengaruh eksentrisitas kolom komposit pipa baja-beton non pasir ditunjukkan dalam hubungan beban dan eksentrisitas. Dari Gambar 7 secara umum terlihat bahwa terjadi penurunan kapasitas aksial akibat eksentrisitas. Semakin besar eksentrisitas, maka kapasitas aksial semakin kecil.

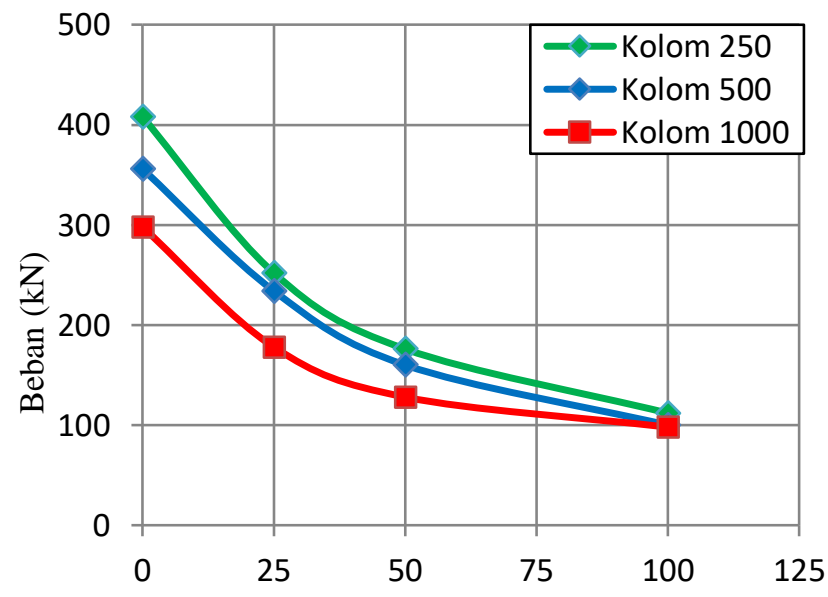

Eksentrisitas

Gambar 6. Diagram beban-eksentrisitas analisis numerik

\subsection{Hubungan Beban-Regangan}

Untuk mendapatkan regangan pada titik yang sama dengan titik dimana dipasang strain gauge pada program eksperimental, pada benda uji numerik ditambahkan monitor for point. Monitor for point yang dipakai pada arah sumbu z. Hasil analisis numerik dapat dilihat pada Gambar 8. Regangan hasil analisis numerik memunjukkan perilaku yang sama dengan eksperimen. Akan tetapi terlihat perbedaan besar regangan antara K3-D hasil eksperimen dengan K3-D hasil analisis numerik, terutama pada bagian awal pembebanan. Hal ini karena keruntuhan analisis numerik bersifat global (lateral) sedangkan hasil eksperimen terjadi keruntuhan lokal. 


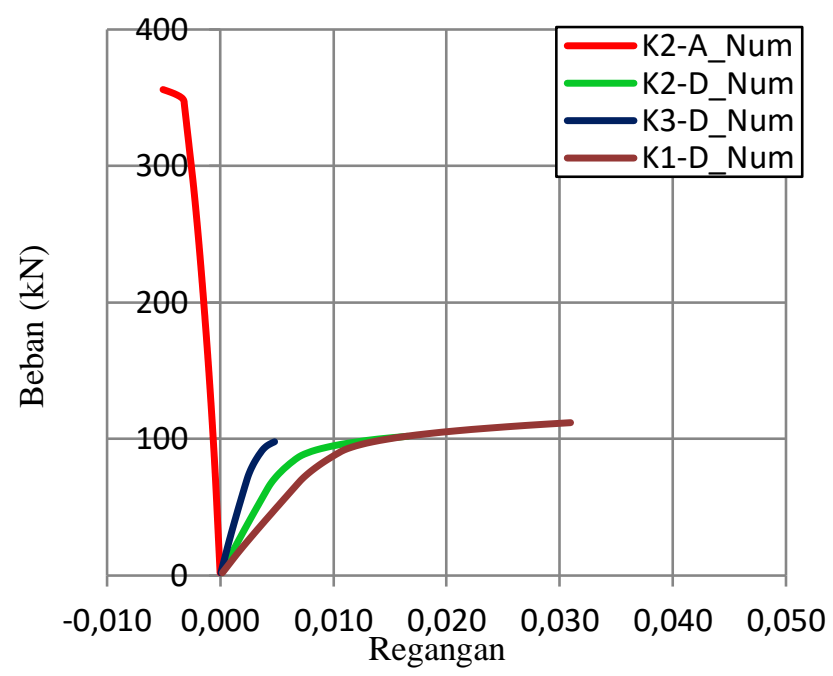

Gambar 8. Diagram beban-regangan hasil analisis numerik

\section{KESIMPULAN DAN SARAN}

\subsection{Kesimpulan}

1. Material baja yang digunakan mempunyai tegangan leleh $358,03 \mathrm{MPa}$, sedangkan beton non pasir mempunyai kuat tekan karakteristik 12,79 MPa dan kuat tarik 1,20 MPa.

2. Kolom komposit pipa baja-beton non pasir dengan beban konsentrik menunjukkan terjadinya peningkatan kapasitas aksial dan daktilitas dibandingkan dengan pipa baja tanpa pengisi dengan peningkatan sebesar 25\% - 36\%.

3. Pola runtuh pipa baja kosong K2 dan K3 berupa tekuk local (local buckling), yang terjadi pada salah satu ujung kolom, sementara sebagian besar tabung masih utuh.

4. Dari analisis numerik, pada umumnya dapat memprediksi kapasitas kolom komposit, tetapi tidak dapat memberikan descending part kurva dan kekakuan awal seperti hasil eksperimen.

5. Pada analisis numerik, dengan eksentrisitas $25 \mathrm{~mm}$ terjadi penurunan kapasitas dukung aksial sebesar $35 \%$ dibandingkan dengan pembebanan konsentrik. Selisih kapasitas dukung aksial sebesar $14 \%$ antara kolom komposit dengan beban eksentris $50 \mathrm{~mm}$ dan eksentris $100 \mathrm{~mm}$.

6. Keruntuhan analisis numerik bersifat global (lateral) sedangkan hasil eksperimen terjadi keruntuhan lokal.

\subsection{Saran}

1. Perlu dilakukan pengujian dengan kolom yang lebih panjang, sehingga menyerupai dengan kondisi riil dilapangan dan dapat lebih jelas melihat pengaruh kelangsingan yang terjadi.

2. Perlu dibuat dudukan/sepatu kolom yang lebih baik, kokoh dan tidak ada penyambungan las dengan benda uji, agar hasil eksperimen menjadi lebih baik.

3. Perlu dilakukan pengujian yang lebih lanjut mengenai properties beton non pasir, dan perlu dilakukan eksplorasi constitutive model yang lebih mendalam.

4. Rentang variasi nilai parameter perlu diperluas untuk mendapatkan pemahaman yang lebih luas mengenai komposit dengan bahan pengisi berupa beton ringan. 
5. Agar hasil eksperimen dapat diekstrapolasikan ke prototipe (tidak hanya untuk model kecil), maka perlu diperhatikan teori model struktur (similaritas, nondimensional) dalam merancang model yang akan diuji.

\section{DAFTAR PUSTAKA}

Basid, A., 2011, "Analisis Kolom Dengan Perkuatan Baja Profil Siku Menggunakan Metode Elemen Hingga", Tesis Pascasarjana Universita Gadjah Mada, Yogyakarta

Cervenka, V., Jendele, L., Cervenka, J., 2006. “ATENA Program Documentation, Part 1, Theory”, Cervenka Consulting, Prague, Czech Republic.

Claeson, C., 1996. "Finite Element Analysis Of Concrete Colums" Division of Concrete Structure Chalmers, University Of Technology, Goteborg, Sweden.

Fam,A., Qie, FS., Rizkalla, S., "Concrete-Filled Steel Tubes to Axial Compression and Lateral Cyclic Loads" Dept. Of Civil Engineering, Queen's University, Kingston, Canada.

Laban, NN., 2010. "Analisis Numrik Perilaku Kolom Penampang lingkaran dengan Kekangan Baja Spiral, CFST dan FRP Akibat Beban Aksial Konsentrik", Tesis Pascasarjana Universitas Gadjah Mada, Yogyakarta.

Muslikh., 2005. "Pengaruh Kekangan Beton Terhadap Interaksi Gaya Aksial Dan Momen Ultimit Pada Kolom Tubular Komposit Lingkaran". Desertasi Program Doktor ITB, Bandung.

Nawy, E.G., 1985. "Beton Bertulang Suatu Pendekatan Mendasar" (diterjemahkan oleh Bambang Suryoatmono", Rafika Aditama, Bandung.

Omar, T.S., Butterworth, J.W., Lowe, P.G., "Development of A Finite Element Model For Concrete Filled Steel Tube Members in Flexure" Tenth International Colloquium on Structural and Geotecnical Engineering, Ain Shams University, Cairo, Egypt.

Rum, G.M., 2009. "Pemanfaatan Berangkal Galunggung Untuk Pembuatan Beton Non Pasir" Tesis Magister Teknologi Bahan Bangunan, Universitas Gadjah Mada, Yogyakarta. 